\title{
Optimum Design of Partially Prestressed Concrete Beams
}

\author{
Mohannad H. Al-Sherrawi ${ }^{1}$ \\ ${ }^{1}$ University of Baghdad, College of Engineering, Civil Eng. Department, Baghdad, Iraq
}

\begin{abstract}
The research presents a formulation for optimum design of partially prestressed concrete beams based on elastic analysis. The optimum design is selected to satisfy the limitations of ACI-Code 2014. The objective function is the cost of the beam. The design variables are the cross-sectional dimensions, the area of strands, and the additional ordinary reinforcement area used. The constraints represent inequality limitations on stresses, ultimate strength capacity, shear, deflection, and practical considerations according to the design requirements. The optimization problem is formulated for several sections like; rectangular, symmetrical I-, T-, and unsymmetrical I-section. The formulation of the optimization problem has been made by utilizing the sequential unconstrained minimization technique (SUMT). The procedure could be used practically by structural engineers.
\end{abstract}

Keywords: partially prestressed, concrete beam, optimization, sumt, cost.

\section{Introduction}

No one type of structural medium can offer the perfect solution to all design situations. However, partially prestressed concrete does offer a number of distinct advantages over ordinary reinforced and prestressed concrete and these advantages do lead to the choice of partially prestressing as a viable design solution.

Partially prestressed concrete construction uses prestressed, or a combination of prestressed and nonprestressed, reinforcement. Partially prestressed concrete falls between the limiting cases of conventionally reinforced concrete and fully prestressed concrete, which allows no flexural tension under service loads. When flexural tensile stresses and cracking are allowed under service loads, the prestressed members have historically been called partially prestressed.

ACI 318-14 [1] defines prestressed concrete as "concrete in which internal stresses have been introduced to reduce potential tensile stresses in concrete resulting from service loads." The design formulas for ultimate load are identical if the yield stress $\left(f_{y}\right)$ used for reinforced concrete is replaced by the stress $\mathrm{f}_{\mathrm{ps}}$ of prestressing steel.

Since different degrees of prestress are possible according to the above definition, beams of various properties can be obtained. These properties can be represented by a family of load-deflection curves (see Figure 1) for under-reinforced Ibeams with well bonded steel. Type (i) shows a member, which is overprestressed to such an extent, that it would crack and fail simultaneously. Type (ii) represents a so-called "fully" prestressed beam, which remains in compression under service load. Type (iii) depicts a "partially" prestressed member in which concrete tensile stresses of desired magnitude occur and cracks of any desired nature may develop under service load. Whereas type (iv) represents an ordinary reinforced or prestressed concrete member in which the initial prestress has become ineffective. All these types of beams have approximately the same failure load.

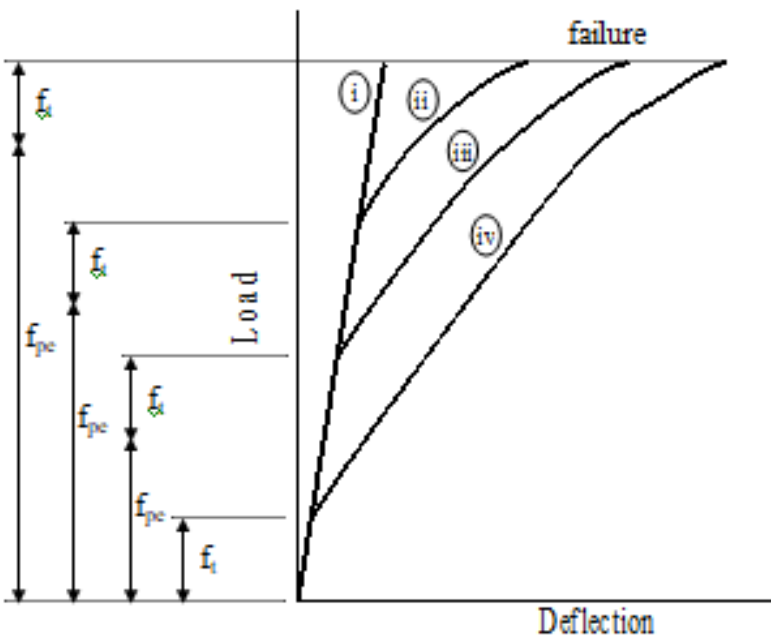

Figure 1: Family of load-deflection curves of reinforced and prestressed concrete beams

Various kinds of partially prestressed concrete beams may be considered, depending on one of the following conditions: whether the member remains in compression under dead load and visible cracks are avoided even under service load: Type (a); or whether temporary cracks of limited width may develop under service load, which close on its removal: Type (b); or whether permanent open cracks of limited width may occur: Type (c). This later case is based on the consideration that if this type is allowed in ordinary reinforced concrete it should also be permitted in prestressed concrete. However, the objection may be made that prestressing steel is more sensitive to corrosion than ordinary reinforcing steel. Experts have different opinions. Nevertheless, there is an advantage to partial (or call it "limited") prestressing because cracks can be limited to a much greater extent than with ordinary reinforced concrete.

Prestressing can be achieved by different tendon configurations as shown in Figure 2. 


\section{International Journal of Science and Research (IJSR) ISSN (Online): 2319-7064}

Index Copernicus Value (2016): 79.57 | Impact Factor (2015): 6.391

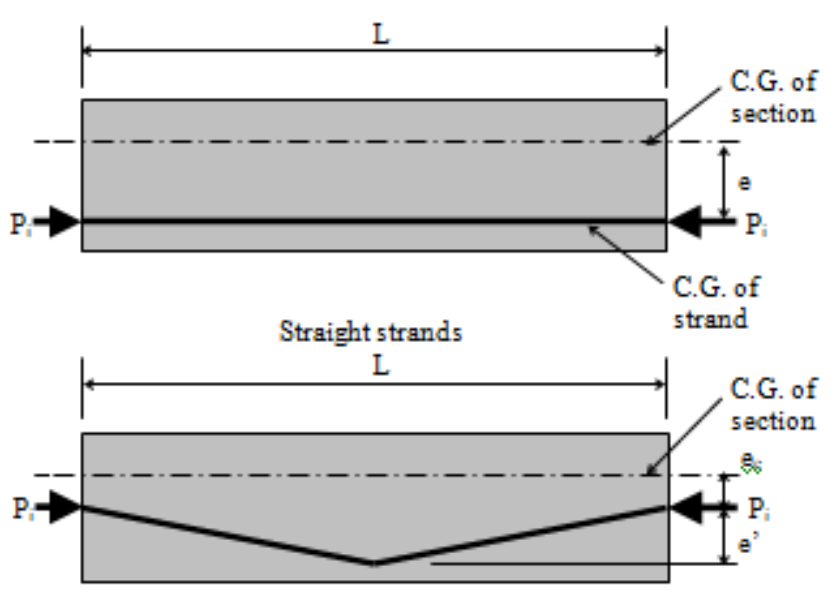

Single point depressed

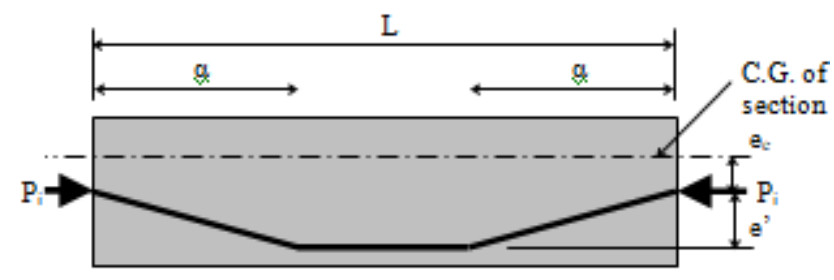

Tow points depressed

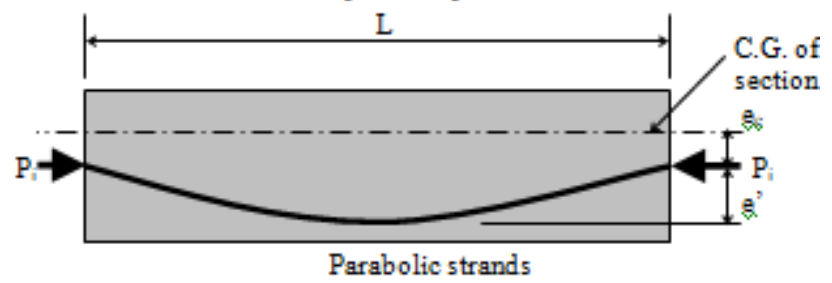

Figure 2: Tendon configurations

Among the various concrete structures, the structural component, which will benefit most from an optimization procedure, is the simply supported, partially prestressed concrete beam. In fact, this element is mass-produced, and it is clear that even minor savings on a single beam could result in a substantial cost reduction. Despite such an incentive for research on the optimization of prestressed concrete beams, this area has received surprisingly little attention [2].

Naaman [3] studied the optimization of prestressed concrete tensile members with two variables, cross-sectional area and area of steel. He showed that both the objective function and the constraints have a linear form.

This study presents a comprehensive solution to the nonlinear optimization of a simply supported, partially prestressed concrete beam with unsymmetrical cross section. Design problems will be optimized assuming cracked and uncracked sections. Qualitative and quantitative conclusions regarding the behavioral characteristics of some design parameters and their interplay will be discussed, and a cost comparison will be made with actual designs.

It is appropriate to mention that while the current literature defines partial prestressing as a process in which tensile stresses and cracking are allowed to occur in a prestressed beam, the author adopt Naaman's [4] proposed definition which is somewhat different ("A necessary and sufficient condition for a member to be called partially prestressed is to contain prestressed and non-prestressed reinforcement intended to resist external loads of the same nature.") and will differentiate between cracked and uncracked partially prestressed beams.

\section{ACI Code Design Assumptions}

Partially prestressed beams are permitted by most design specifications. While ACI Code does not mention partial prestressing explicitly, the Code permits the computed stress in tension to pass $\sqrt{f_{c}^{\prime}}$, well above the usual modulus of rupture, in ordinary design of prestressed members. Furthermore, equations for flexural strength in ACI Code and Commentary account explicitly for the presence of both nonprestressed and prestressed flexural tension steel.

ACI Code classified prestressed flexural members as Class $\mathrm{U}$, Class T, or Class $\mathrm{C}$ based on the computed extreme fiber stress in tension in the precompressed tensile zone calculated at service loads using gross section properties $\left(\mathrm{f}_{\mathrm{t}}\right)$ as follows:

(a) Class $\mathrm{U}: f_{t} \leq 0.62 \sqrt{f_{c}^{\prime}}$

(b) Class T: $0.62 \sqrt{f_{c}^{\prime}}<f_{t} \leq 1.0 \sqrt{f_{c}^{\prime}}$

(c) Class C: $f_{t}>1.0 \sqrt{f_{c}^{\prime}}$

It can be seen that the Code defines three classes of behavior of prestressed flexural members; Class $U$ members are assumed to behave as uncracked members. Class $\mathrm{C}$ members are assumed to behave as cracked members. The behavior of Class $\mathrm{T}$ members is assumed to be in transition between uncracked and cracked.

For Class U and Class T flexural members, stresses at service loads shall be permitted to be calculated using the uncracked section. For Class C flexural members, stresses at service loads shall be calculated using the cracked transformed section.

\section{Problem Formulation}

The method has been formulated for a general I-shaped cross section with six geometrical design variables denoted by $\mathrm{x}_{1}$ through $\mathrm{x}_{6}$, see Figure 3 . Also three other variables $\mathrm{x}_{7}, \mathrm{x}_{8}$, and $x_{9}$, representing the area of prestressing steel, the area of bottom tensile steel, and the area of top compressive steel respectively, were used. It is assumed that for maximum efficiency the eccentricity takes its largest allowable value at mid-span (with minimum concrete cover), and that the initial prestressing stress (after prestress transfer) is also at its maximum allowable value of $0.70 f_{\text {pu }}$ [ACI 318-14].

\section{Volume 6 Issue 12, December 2017 www.ijsr.net}




\section{International Journal of Science and Research (IJSR) \\ ISSN (Online): 2319-7064}

Index Copernicus Value (2016): 79.57 | Impact Factor (2015): 6.391

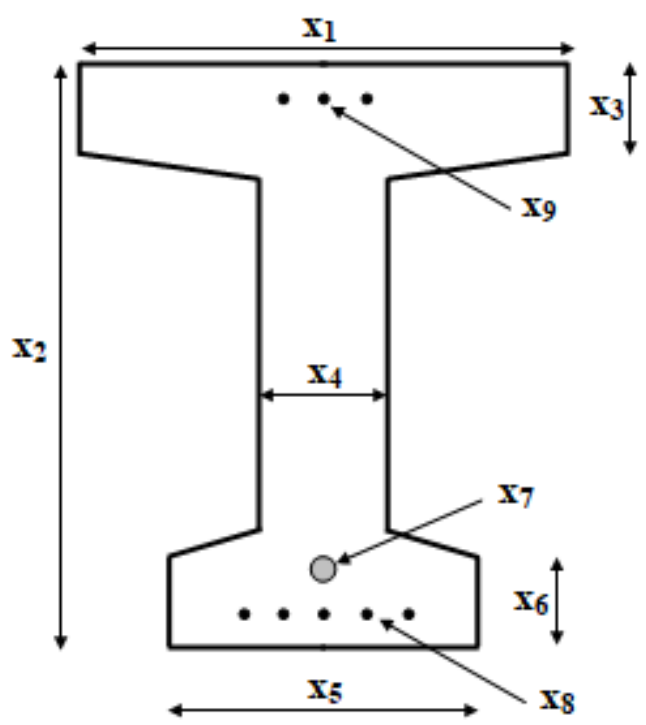

Figure 3: Geometrical and steel design variables in a general I-shaped cross section

The cost function to be minimized is denoted by $\mathrm{Z}$ and the constraint functions by $\mathrm{g}(\mathrm{x})$. The optimization problem can thus be written as:

$$
Z=A_{c} \cdot L \cdot C_{c}+A_{p s} \cdot L \cdot C_{p s}+A_{o s} \cdot L \cdot C_{o s}
$$

in which $\mathrm{A}_{\mathrm{c}}, \mathrm{A}_{\mathrm{ps}}, \mathrm{A}_{\mathrm{os}}$ are the concrete cross-sectional area, prestressed strand area, ordinary reinforced steel area respectively; $\mathrm{L}$ the length of the beam; and $\mathrm{C}_{\mathrm{c}}, \mathrm{C}_{\mathrm{ps}}, \mathrm{C}_{\mathrm{os}}$ the cost of concrete, prestressed strand, ordinary reinforced steel. The costs of forming, casting concrete, and shear reinforcement are not included.

Subjected to $g_{i}(x) \geq 0 \quad \mathrm{i}=0,11 \quad$ and $x_{i} \geq 0 \quad \mathrm{i}=0,9$.

The following behavior constraints were considered:

1) Flexural stresses (four).

2) Initial camber.

3) Dead load deflection.

4) Live load deflection.

5) The final deflection.

6) Ultimate moment capacity of the section with reference to the factored load and the cracking moment.

7) Shear strength.

\section{Derivation of Constraints Inequalities}

\subsection{Normal stresses}

There are two critical loading stages that the section will experience. The first is the transfer stage which is the application of the self-weight effects simultaneously with the prestressing force. The second stage, working (service) load, occurs with the addition of the full superimposed load (live load plus dead load added after transfer). The acting of a load on a typical partially prestressed simply supported beam at the critical section (end of pre-tension beam at the transfer stage and mid span of pre-tension beam at the working load stage and post-tension beam at both stages) with the stress distribution is illustrated in Figure 4. The initial top (denoted by 1) and bottom (denoted by 2) stresses are then respectively given by:

$$
\begin{aligned}
& f_{1 i}=-\frac{P_{i}}{A_{c}}\left(1-\frac{e \cdot c_{1}}{r^{2}}\right)-\frac{\alpha \cdot M_{s} \cdot c_{1}}{I_{g}} \\
& f_{2 i}=-\frac{P_{i}}{A_{c}}\left(1+\frac{e \cdot c_{2}}{r^{2}}\right)+\frac{\alpha \cdot M_{s} \cdot c_{2}}{I_{g}}
\end{aligned}
$$

where $P_{i}$ is the initial prestressing force, $c_{1}$ and $c_{2}$ are the distance between the neutral axis and the top and bottom fibers respectively, $I_{g}$ is the moment of inertia of the uncracked cross section, $r$ is the radius of gyration, $M_{s}$ is the moment caused by beam's own self weight, and

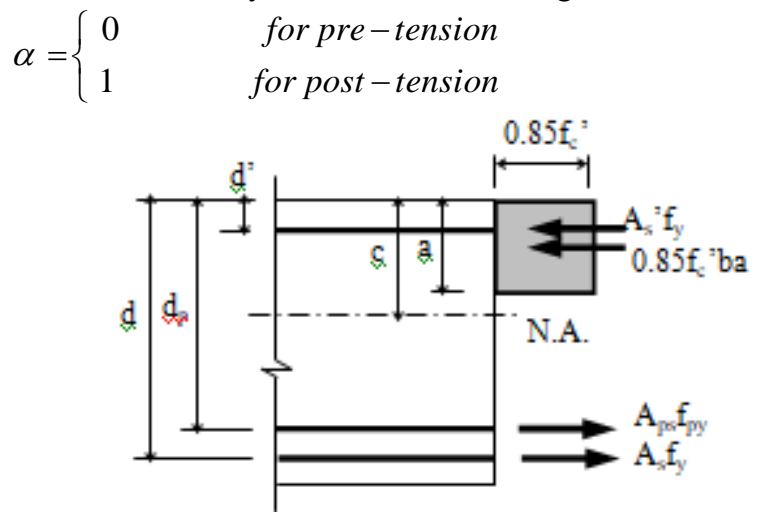

Figure 4: Stress distribution at the critical section

It must be noted that the sign convention is the tensile stress is positive and the compressive stress is negative, the eccentricity is considered positive when it lies below the centroid.

At working stage, assuming an uncracked section, the flexural stresses at the top and bottom fibers are respectively given by:

$$
\begin{aligned}
& f_{1}=-\frac{P_{e}}{A_{c}}\left(1-\frac{e \cdot c_{1}}{r^{2}}\right)-\frac{\left(M_{s}+M_{d}+M_{l}\right) \cdot c_{1}}{I_{g}} \\
& f_{2}=-\frac{P_{e}}{A_{c}}\left(1+\frac{e \cdot c_{2}}{r^{2}}\right)+\frac{\left(M_{s}+M_{d}+M_{l}\right) \cdot c_{2}}{I_{g}}
\end{aligned}
$$

in which $\mathrm{P}_{\mathrm{e}}$ is the effective prestressing force (remaining after all losses take place), and $M_{d}$ and $M_{1}$ are the dead and live load moments. If $\mathrm{f}_{2}$ exceeds the concrete modulus of rupture $\left(f_{r}\right)$, then $f_{1}$ should be computed on the basis of cracked section and $f_{2}$ will be zero. Nilson [5] has shown that in such a case the compressive stress is given by:

$$
f_{1}=-\frac{P_{f}}{A_{c r}}-\frac{P_{f} \cdot e^{*} \cdot c_{1}^{*}}{I_{c r}}
$$

in which

$$
\begin{aligned}
& P_{f}=P_{e} \cdot\left[1+\frac{E_{p}}{E_{c}} \cdot A_{c} \cdot\left(1+\frac{e^{2}}{r^{2}}\right)\right] \\
& e^{*}=\frac{M_{s}+M_{d}+M_{l}-P_{e} \cdot e}{P_{f}}-c_{1}+c_{1}^{*}
\end{aligned}
$$

and $c_{1}{ }^{*}$ is the distance from the top of the member to the centroid of the cracked concrete section. 


\section{International Journal of Science and Research (IJSR) \\ ISSN (Online): 2319-7064}

Index Copernicus Value (2016): 79.57 | Impact Factor (2015): 6.391

It would be important to make a distinction between the prestress force of the tendon and the reduction of the concrete force which is equal to the loss of prestress plus the force in non-tensioned steel. Thereby, prestress losses are strongly affected by the presence of non-tensioned steel.

Top and bottom fiber normal stresses should be within the allowable limits specified by ACI 318-14, resulting in the following inequality constraints:

$$
\begin{aligned}
& g(1)=\frac{f_{2 i}}{f_{c i}}-1>0 \\
& g(2)=\frac{f_{t i}}{f_{1 i}}-1>0 \\
& g(3)=\frac{f_{1 s}}{f_{c s}}-1>0 \\
& g(4)=\frac{f_{t s}}{f_{2 s}}-1>0
\end{aligned}
$$

In which $\mathrm{f}_{\mathrm{ti}}$ and $\mathrm{f}_{\mathrm{ci}}$ are the allowable tensile and compressive initial stresses and $f_{t s}$ and $f_{c s}$ are the allowable tensile and compressive service stresses.

It should be noted that when the section is uncracked ( $f_{2 s}$ less than the modulus of rupture), $\mathrm{f}_{1 \mathrm{~s}}$ is computed from Equation (4). When the section is cracked, $f_{1 s}$ is computed from Equation (6), and g(4) is assigned an arbitrary large value.

Permissible stresses in concrete and prestressing steel:

1) The stresses in concrete immediately after prestress transfer (before time dependent prestress losses) shall not exceed the following:

a. Extreme fiber stress in compression ............................... $0.6 f_{c i}^{\prime}$

b. Extreme fiber stress in tension except as permited in c........................... 0.25 $\sqrt{f_{c i}^{\prime}}$

c. Extreme fiber stress in tension at ends of simply supported members.......... 0.5 $\sqrt{f_{c i}^{\prime}}$

2) The stresses in concrete at service loads (after allowance for all prestress losses) shall not exceed the following:

a. Extreme fiber stress in compression due to prestress plus sustained loads $0.45 f_{c}$

b. Extreme fiber stress in compression due to prestress plus total load $0.6 f_{c}^{\prime}$

c. Extreme fiber stress in tension in precompressed tensile zone

$$
0.62 \sqrt{f_{c}^{\prime}}
$$

Tensile stress in prestressing steel shall not exceed the following:

Immediately after prestress transfer....... $0.82 \mathrm{f}_{\mathrm{py}}$ but not greater than $0.74 \mathrm{f}_{\mathrm{pu}}$.

\subsection{Deflection constraints}

The deflections at initial stage and long-term are considered as an important phase for the design of partially prestressed concrete beams. The initial stage is occurred when the beam is acted upon by the initial prestress force $\left(\mathrm{P}_{\mathrm{i}}\right)$ and its own weight. After this stage the deflection is modified due to prestressing losses and to the developed deflections due to concrete creep under sustained loads and shrinkage. The downward deflection of the beam caused by its own self weight is:

$$
\Delta_{s}=\frac{5 w_{s} \cdot L^{4}}{384 E_{c} \cdot I_{g}}
$$

This deflection is opposed by an initial upward camber caused by the prestressing cable given by:

$$
\Delta_{p i}= \begin{cases}\frac{P_{i} \cdot e \cdot L^{2}}{8 E_{c} \cdot I_{g}} & \text { straight tendon } \\ \frac{P_{i} \cdot e_{e} \cdot L^{2}}{8 E_{c} \cdot I_{g}}+\frac{P_{i} \cdot e^{\prime} \cdot L^{2}}{12 E_{c} \cdot I_{g}} & \text { single point depressed } \\ \frac{P_{i} \cdot e_{e} \cdot L^{2}}{8 E_{c} \cdot I_{g}}+\frac{P_{i} \cdot e^{\prime}}{E_{c} \cdot I_{g}} \cdot\left(\frac{L^{2}}{8}-\frac{\alpha^{2}}{6}\right) & \text { tow points depressed } \\ \frac{P_{i} \cdot e_{e} \cdot L^{2}}{8 E_{c} \cdot I_{g}}+\frac{5 P_{i} \cdot e^{\prime} \cdot L^{2}}{48 E_{c} \cdot I_{g}} & \text { parabolic tendon }\end{cases}
$$

The initial camber stage occurred due to the initial prestress and the self-weight of the beam [6].

$$
\Delta_{i}=-\Delta_{p i}+\Delta_{s} \geq \bar{\Delta}_{i}
$$

where $\bar{\Delta}_{i}$ is the allowable initial upward camber (negative value).

Then the inequality constraint becomes:

$$
g(5)=1-\frac{\Delta_{s}+\Delta_{p i}}{\bar{\Delta}_{i}}>0
$$

The dead load (beam's self-weight and all additional dead load) deflection, without time dependent effects, is:

$$
\Delta_{d i}=\frac{5 w_{d} \cdot L^{4}}{384 E_{c} \cdot I_{e}}
$$

in which

$$
\begin{aligned}
& I_{e}=\left(\frac{M_{c r}}{M_{\max }}\right)^{3} \cdot I_{g}+\left[1-\left(\frac{M_{c r}}{M_{\max }}\right)^{3}\right] . I_{c r} \leq I_{g} \\
& \text { and } M_{c r}=f_{r} . S_{2}+P_{e} \cdot\left(\frac{r^{2}}{c_{2}}+e\right)
\end{aligned}
$$

Shaikh and Branson [7] showed that the $I_{e}$ method can be used to compute deflections of partially prestressed beams loaded above the cracking load. For this case, the cracking moment must take into account the effect of prestress.

Finally, it can be shown [6] that the long term dead load deflection, after all losses and creep when the effective prestress force and the dead load act, can be adequately calculated from:

$$
\Delta_{d}=-\Delta_{p e}-\left(\Delta_{p i}+\Delta_{p e}\right) \cdot \frac{C_{u}}{2}+\Delta_{d i} \cdot\left(1+C_{u}\right)
$$

in which $\mathrm{C}_{\mathrm{u}}$ is the creep coefficient and

$$
\Delta_{p e}=\Delta_{p i} \cdot\left(\frac{P_{e}}{P_{i}}\right)
$$

With $\bar{\Delta}_{d}$ (positive downward) as the maximum allowable long term dead load deflection, the constraint becomes:

$$
g(6)=1-\frac{\Delta_{d}}{\bar{\Delta}_{d}}>0
$$

\section{Volume 6 Issue 12, December 2017}




\section{International Journal of Science and Research (IJSR) \\ ISSN (Online): 2319-7064}

Index Copernicus Value (2016): 79.57 | Impact Factor (2015): 6.391

Another constraint on the live load deflection should be considered:

$$
g(7)=1-\frac{\Delta_{l}}{\bar{\Delta}_{l}}>0
$$

where $\Delta_{l}$ is the deflection due to superimposed live load, and $\bar{\Delta}_{l}$ is the allowable live load deflection.

The final deflection position of the beam will be the combination of the above stages as follows [6]:

$$
\Delta=\Delta_{d}+\Delta_{l} \leq \bar{\Delta}
$$

where $\bar{\Delta}$ is the maximum allowable deflection.

Then the inequality constraint becomes:

$$
g(8)=1-\frac{\Delta}{\bar{\Delta}}>0
$$

ACI Code state that immediate deflections of Class $U$ prestressed concrete members may be calculated by the usual methods or formulas for elastic deflections using the moment of inertia of the gross (uncracked) concrete section. While for Class $\mathrm{C}$ and Class $\mathrm{T}$ flexural members deflection calculations shall be based on a cracked transformed section analysis. It shall be permitted to base computations on a bilinear moment-deflection relationship, or an effective moment of inertia $\left(I_{e}\right)$.

Additional long-term deflection of prestressed concrete members shall be computed taking into account stresses in concrete and steel under sustained load and including effects of creep and shrinkage of concrete and relaxation of steel.

The Code requires that "bilinear moment-deflection relationships" be used to calculate instantaneous deflections of prestressed concrete members when the bottom tension exceeds $0.62 \sqrt{f_{c}^{\prime}}$. This means that the deflection before the member has cracked is calculated using the gross (uncracked) moment of inertia $\left(\mathrm{I}_{\mathrm{g}}\right)$ and the additional deflection after cracking is calculated using the moment of inertia of the cracked section [8]. This is illustrated graphically in Figure 5.

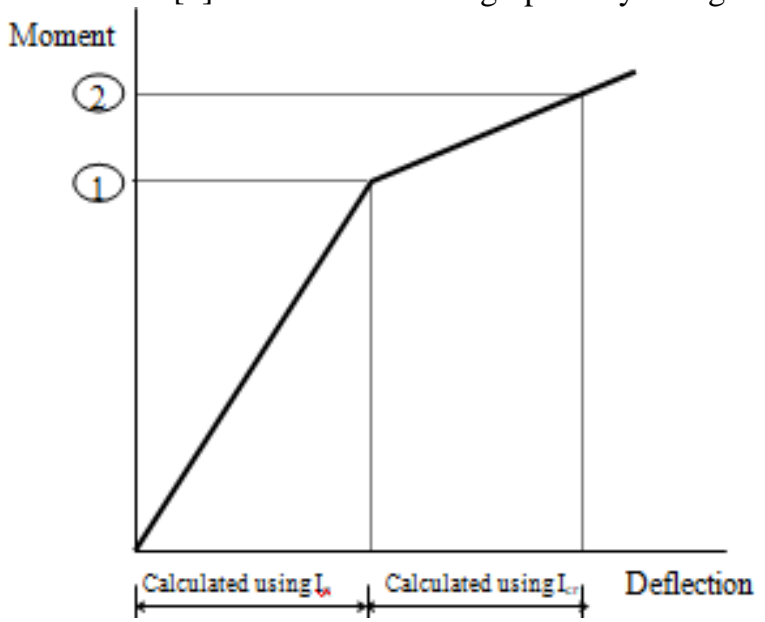

Figure 5: Bilinear moment-deflection relationship

The Code allows an alternative to the method of calculation described in the previous paragraph. An effective moment of inertia $\left(I_{e}\right)$ can be determined and the deflection then calculated by substituting $I_{e}$ for $I_{g}$ in the deflection calculation. The difference between the bilinear method and the $I_{e}$ method is illustrated in Figure 6.

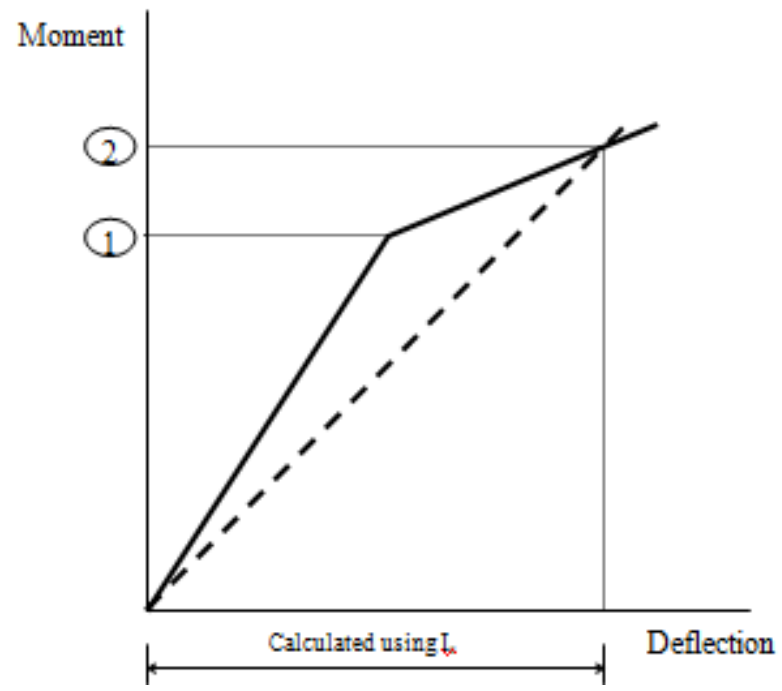

Figure 6: The difference between the bilinear method and the $I_{e}$ method

Mast [9] gave additional information on the deflection of cracked prestressed concrete members.

\subsection{Ultimate moment capacity}

Naaman [10] showed that two relations exist between $\mathrm{f}_{\mathrm{ps}}$ and $\varepsilon_{p s}$. The first is of the form:

$$
f_{p s}=\frac{A}{\varepsilon_{p s}+B}+C . \varepsilon_{p s}+D
$$

where $\mathrm{A}, \mathrm{B}, \mathrm{C}$, and $\mathrm{D}$ are parameters depending on material characteristics, effective prestress, mild steel reinforcement, and properties of the section. The derivation of this equation is based on equilibrium consideration with linear strain distribution at failure.

The other relationship, between $\mathrm{f}_{\mathrm{ps}}$ and $\varepsilon_{p s}$, is the one experimentally derived for each type of prestressing reinforcement. Typically, such a curve is divided into three parts: linear, nonlinear, and linear. Using curve fitting techniques, equations for stress strain curves of prestressing strands and prestressing bars were determined by Naaman with a maximum error of $0.4 \%$ (Figure 7 ). 


\section{International Journal of Science and Research (IJSR) \\ ISSN (Online): 2319-7064}

Index Copernicus Value (2016): 79.57 | Impact Factor (2015): 6.391

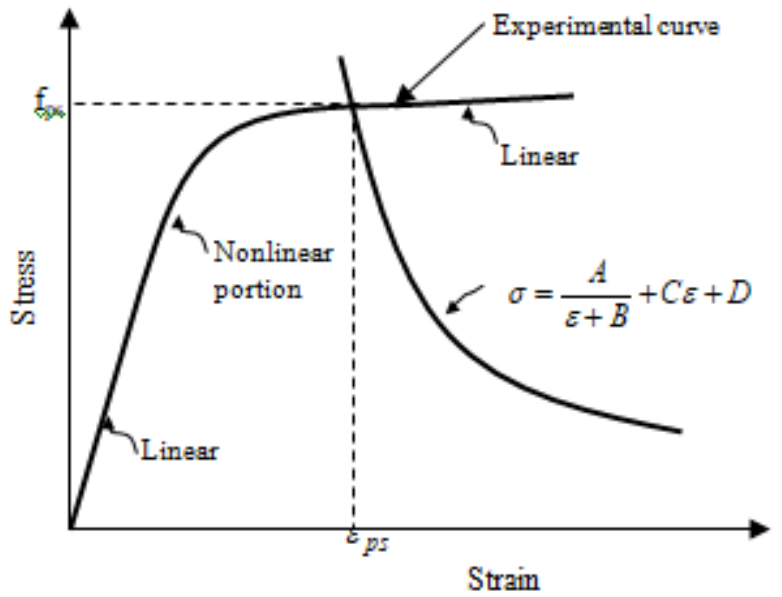

Figure 7: Stress strain relations [10]

At failure, $\mathrm{f}_{\mathrm{ps}}$ and $\varepsilon_{p s}$ have to satisfy both equations simultaneously. To find the intersection of the two equations a numerical technique is employed. Once $f_{p s}$ has been determined, then the ultimate moment capacity $M_{n}$ can be easily computed. Four different expressions exist for $M_{n}$ depending on whether there is an over or under-reinforced rectangular or T-section. For the sake of clarity those expressions will not be given here, but can be found in [10].

Once $M_{n}$ has been determined, then the inequality constraint with respect to the cracking moment becomes

$$
g(9)=\frac{M_{n}}{\beta \cdot M_{c r}}-1>0
$$

where

$\beta= \begin{cases}>1.0 & \text { uncracked section } \\ <1.0 & \text { cracked section }\end{cases}$

and the inequality constraint with respect to the ultimate applied moment $\left(\mathrm{M}_{\max }\right)$ becomes

$$
g(10)=\frac{M_{n}}{M_{\max }}-1>0
$$

\subsection{Shear strength}

The critical section for shear is assumed to occur at L/4 from the support [6]. The resisting nominal shear, provided by concrete $\mathrm{V}_{\mathrm{c}}$, is given by:

$$
V_{c}=\min \left(V_{c w}, V_{c i}\right)
$$

where $\mathrm{V}_{\mathrm{cw}}$ is the nominal shear strength corresponding to web shear cracking. This is given by [1]:

$$
V_{c w}=\left(0.29 \sqrt{f_{c}^{\prime}}+0.3 f_{p c}\right) \cdot b_{w} \cdot d_{p}+V_{p}
$$

$\theta$ is the slop of the tendon at the considered section, $\mathrm{V}_{\mathrm{p}}$ is the vertical component of the effective prestress:

$$
V_{p}=P_{e} \cdot \sin \theta
$$

$\mathrm{V}_{\mathrm{ci}}$ is the flexure-shear strength and is given by [1]:

$$
V_{c i}=\max \cdot\left\{\begin{array}{c}
0.05 \sqrt{f_{c}^{\prime}} \cdot b_{w} \cdot d_{p}+V_{d}+\frac{V_{i} \cdot M_{c r e}}{M_{\max }} \\
0.14 \sqrt{f_{c}^{\prime}} \cdot b_{w} \cdot d_{p}
\end{array}\right.
$$

Since there are no design provisions for shear reinforcement, $\mathrm{V}_{\mathrm{c}}$ is arbitrarily increased by $20 \%$ to reflect the increased strength, which could easily be provided by vertical reinforcements. With $\mathrm{V}_{\max }$, the ultimate shear at $\mathrm{L} / 4$ is given by:

$$
V_{\max }=\frac{w_{u}^{1}}{4}
$$

and the shear constraint becomes

$$
g(11)=\frac{V_{c}}{V_{\max }}-1>0
$$

\subsection{Design constraints}

In addition to the eleven behavior constraints, there were nine geometrical constraints. The first required that the web width be greater than $75 \mathrm{~mm}$, and the other eight simply required each physical dimension (except the web width) to remain positive $[\mathrm{g}(13)-\mathrm{g}(20)]$.

\section{Optimization Procedure}

The minimum cost for the design of partially prestressed concrete beams is the objective. Two types of objective functions are considered in this study: the first one is for a beam with predefined cross sectional dimensions, while the second one is for a beam with variable cross sectional dimensions.

The constraints indicated above and the objective function are then used to define a non-linear program. The solution is carried out using the sequential unconstrained minimization technique (SUMT) algorithm to minimize the objective function and to get the optimum solution of the design variables.

In this study, the interior penalty function has been used with all constraints are inequalities:

$$
\phi(x, r)=f(x)+r \cdot \sum_{j=1}^{n} \frac{1}{g_{j}(x)}
$$

The function is minimized for a decreasing sequence of values of $\mathrm{r}$ [11]. To accelerate the optimum operation and convergence the $\phi(x, r)$ to the real function $f(x)$ a reduction factor on $\mathrm{r}$ has been used:

$$
r_{k+1}=\frac{r_{k}}{10}
$$

where $\mathrm{k}$ is the iteration number.

A computer program for the optimum design of partially prestressed concrete beams has been written in Microsoft Quick Basic version 4.5 to comprise the formulation of optimization presented in this study. The optimum solution shall need several attempts to ensure the optimality. 


\section{International Journal of Science and Research (IJSR) \\ ISSN (Online): 2319-7064}

Index Copernicus Value (2016): 79.57 | Impact Factor (2015): 6.391

\section{Applications}

\subsection{Constant dimensions}

One of Hamorabi Company prestressed concrete I-beam for highway bridges was investigated. Its dimensions and properties are shown in Figure 8. The beam is optimized as uncracked section with predefined dimensions. The original beam is designed to carry a bending moment equals 750 kN.m.

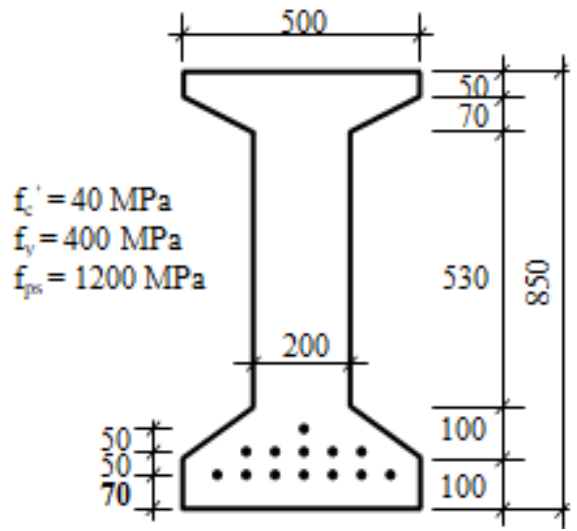

Figure 8: Dimensions and properties of one of Hamorabi prestressed concrete I-beam for highway bridges.

Figure 9 shows the variation in the cost of one beam as the prestressed strand replaced gradually by ordinary reinforcement for different ordinary reinforcement cost to prestressed strand cost ratios. It can be seen that replacing the prestressed strand with ordinary reinforcement when the ratio is more than $1 / 1.75$ can reduce the cost of the beam.

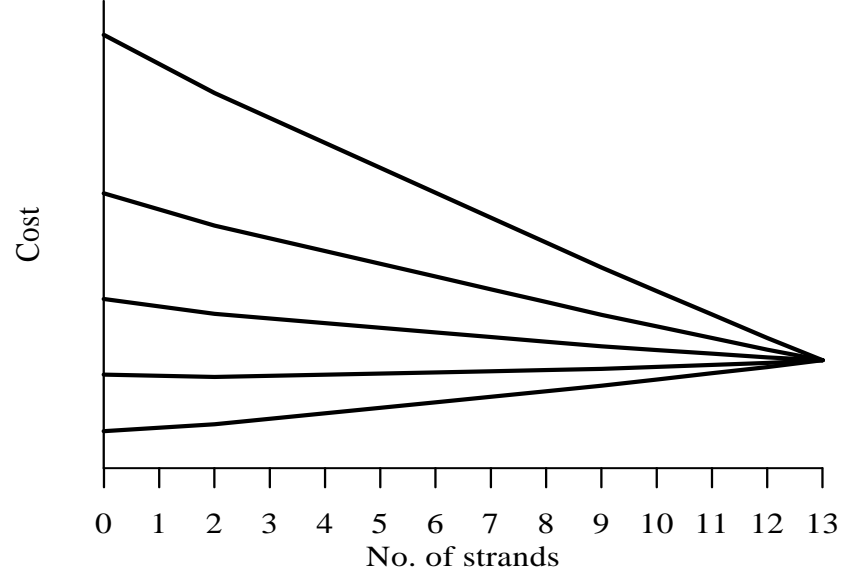

Figure 9: The variation in the cost

\subsection{Variable dimensions}

For partially prestressed concrete beam with rectangular cross section and has compression reinforcement, the ultimate moment capacity equals to:

where

$$
M_{n}=M_{n 1}+M_{n 2}
$$

$$
\begin{gathered}
M_{n 1}=A_{s}^{\prime} \cdot f_{y} \cdot\left(d \text { or } d_{p}-d^{\prime}\right) \\
M_{n 2}=A_{p s} \cdot f_{p s} \cdot\left(d_{p}-\frac{a}{2}\right)+A_{s} \cdot f_{y} \cdot\left(d-\frac{a}{2}\right)-A_{s}^{\prime} \cdot f_{y} \cdot\left(d \text { or } d_{p}-\frac{a}{2}\right) \\
a=\frac{A_{p s} \cdot f_{p s}+A_{s} \cdot f_{s}-A_{s}^{\prime} \cdot f_{y}}{0.85 f_{c}^{\prime} \cdot b}
\end{gathered}
$$

To design a rectangular beam to carry a specific ultimate moment capacity $\left(\mathrm{M}_{\mathrm{u}}\right)$, the beam was optimized with variable cross sectional dimensions. The beam is optimized as an uncracked and cracked section. The final design variables and cost of the uncracked and cracked sections are indicated in Tables 1 and 2 respectively for seven deferent ultimate moment capacities. It should be noted that the final stresses and deflection could easily be obtained from the program.

Table 1: Final values of the design variables and the cost, uncracked section

\begin{tabular}{|c|c|c|c|c|c|}
\hline $\begin{array}{c}M_{u} \\
(k N . m)\end{array}$ & $\begin{array}{c}b \\
(\mathrm{~mm})\end{array}$ & $\begin{array}{c}D \\
(\mathrm{~mm})\end{array}$ & $\begin{array}{c}A_{o s} \\
\left(\mathrm{~mm}^{2}\right)\end{array}$ & $\begin{array}{c}A_{p s} \\
\left(\mathrm{~mm}^{2}\right)\end{array}$ & $\begin{array}{c}\text { Cost } \\
(\text { units })\end{array}$ \\
\hline 50 & 200 & 600 & 80 & 75 & 9.312 \\
\hline 100 & 200 & 740 & 100 & 100 & 11.568 \\
\hline 150 & 240 & 780 & 100 & 150 & 14.664 \\
\hline 200 & 280 & 800 & 100 & 200 & 17.580 \\
\hline 250 & 360 & 780 & 125 & 275 & 22.074 \\
\hline 300 & 400 & 800 & 125 & 325 & 24.917 \\
\hline 350 & 460 & 800 & 150 & 375 & 28.926 \\
\hline
\end{tabular}

Table 2: Final values of the design variables and the cost, cracked section

\begin{tabular}{|c|c|c|c|c|c|}
\hline $\begin{array}{c}M_{u} \\
(\mathrm{kN.m})\end{array}$ & $\begin{array}{c}b \\
(\mathrm{~mm})\end{array}$ & $\begin{array}{c}d \\
(\mathrm{~mm})\end{array}$ & $\begin{array}{c}A_{o s} \\
\left(\mathrm{~mm}^{2}\right)\end{array}$ & $\begin{array}{c}A_{p s} \\
\left(\mathrm{~mm}^{2}\right)\end{array}$ & $\begin{array}{c}\text { Cost } \\
(\text { units })\end{array}$ \\
\hline 50 & 200 & 380 & 100 & 125 & 6.246 \\
\hline 100 & 200 & 520 & 150 & 150 & 8.502 \\
\hline 150 & 200 & 600 & 100 & 225 & 9.858 \\
\hline 200 & 200 & 660 & 100 & 275 & 10.914 \\
\hline 250 & 200 & 740 & 125 & 300 & 12.192 \\
\hline 300 & 200 & 780 & 175 & 325 & 13.171 \\
\hline 350 & 220 & 800 & 200 & 350 & 14.604 \\
\hline
\end{tabular}

Table 3 shows comparisons between the costs for uncracked and cracked sections for the seven deferent ultimate moment capacities. It can be notice that the design of the beam as a

\begin{tabular}{|c|c|c|c|}
\hline \multirow{2}{*}{$\begin{array}{c}M_{u} \\
(k N . m)\end{array}$} & \multicolumn{2}{|c|}{ Cost (units) } & \multirow{2}{*}{$\begin{array}{c}\text { Benefit } \\
(\%)\end{array}$} \\
\hline & $\begin{array}{c}\text { uncracked } \\
\text { section }\end{array}$ & $\begin{array}{c}\text { cracked } \\
\text { section }\end{array}$ & \\
\hline 50 & 9.312 & 6.246 & 32.925 \\
\hline 100 & 11.568 & 8.502 & 26.504 \\
\hline 150 & 14.664 & 9.858 & 32.774 \\
\hline 200 & 17.580 & 10.914 & 37.918 \\
\hline 250 & 22.074 & 12.192 & 44.768 \\
\hline 300 & 24.917 & 13.171 & 47.141 \\
\hline 350 & 28.926 & 14.604 & 49.513 \\
\hline
\end{tabular}
cracked section has the benefit of reducing the cost from $27 \%-50 \%$

Table 3: comparisons between the costs

\section{Conclusions}

Using the SUMT algorithm to minimize the objective function, the optimum design of partially prestressed, simply supported concrete beams with several sections has been presented. For a beam with constant dimensions, a reduction in the cost of the beam can be gained when replacing the prestressed strand with ordinary reinforcement when the ratio of costs is more than $1 / 1.75$. For sections with variable dimensions, cost reduction ranged from $27 \%-50 \%$. 


\section{References}

[1] ACI 318, Building Code Requirements for Structural Concrete (ACI 318-14) and Commentary (ACI 318R14), ACI Committee 318, American Concrete Institute, Farmington Hills, MI, 2014.

[2] O. Lev, "Structural Optimization, Recent Developments and Applications." ASCE, special publications 1981.

[3] A. E. Naaman, "Optimum Design of Prestressed Concrete Tension Members." Journal of the Structural Division, ASCE, Vol. 108, No. ST8, pp. 1722-1738, 1982.

[4] A. E. Naaman, "A Proposal to Extend Some Code Provisions on Reinforcement to Partial Prestressing." Journal of Prestressed Concrete Institute, Vol. 26, No. 2, Mar.- Apr., pp. 75-91, 1981.

[5] A. H. Nilson, "Flexural Stresses after Cracking in Partially Prestressed Beams." Journal of Prestressed Concrete Institute, Vol. 21, No. 4, Aug., pp. 72-81, 1976.

[6] A. H. Nilson, Design of Prestressed Concrete, John Wiley and Sons Inc, New York, N. Y., 1978.

[7] A. F. Shaikh, and D. E. Branson, "Non-Tensioned Steel in Prestressed Concrete Beams," Journal of Prestressed Concrete Institute, Vol. 15, No. 1, Feb., pp. 14-36, 1970.

[8] PCI Design Handbook - Precast and Prestressed Concrete, $7^{\text {th }}$ Edition, Precast/Prestressed Concrete Institute, Chicago, IL, 2010.

[9] R.F. Mast, "Analysis of Cracked Prestressed Concrete Sections: A Practical Approach," Journal of Prestressed Concrete Institute, Vol. 43, No. 4, July-Aug., pp. 80-91, 1998.

[10] A. E. Naaman, "Ultimate Analysis of Prestressed and Partially Prestressed Section by Strain Compatibility." Journal of Prestressed Concrete Institute, Vol. 22, No. 1, Jan., pp. 32-51, 1977.

[11] B. D. Bunday, Basic Optimization Methods, Edward Arnold, London, 1985.

\section{Author Profile}

Mohannad H. Al-Sherrawi received his B.Sc. in civil engineering in 1989, M.Sc. in structural engineering in 1996 and Ph.D in structural engineering in 2001 from University of Baghdad, Baghdad, Iraq. He has 28 years of experience in the design and construction field as structural engineer. Currently, he is an instructor in University of Baghdad.

Volume 6 Issue 12, December 2017 